\section{Cultura material e patrimônio da ciência e tecnologia}

\author{
Por Diogo Jorge de Melo e Rondelly Soares Cavulla"l \\ 'Universidade Federal do Pará \\ "Scientia Consultoria Científica \\ (diogojmelo@gmail.com; rondelly1@gmail.com)
}

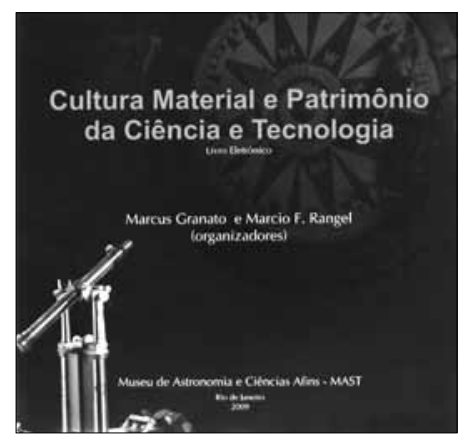

comportamentos científicos, que ocorreram ao longo do tempo, assim como nas concepções estruturais de saberes. Este fato acende a importância de uma política de preservação dos objetos usados pela ciência, demanda cuja origem pode ser datada com o surgimento da denominada segunda geração de museus de ciência², que começou a preservar e expor objetos ligados ao universo da Ciência e Tecnologia, fato decorrente das grandes exposições internacionais ${ }^{3}$.

Seguindo as concepções apresentadas, o Museu de Astronomia e Ciências Afins (MAST), do Ministério da Ciência e Tecnologia, é uma das instituições brasileiras mais preocupadas com a preservação dos objetos ligados aos fazeres científicos, até pelo fato de que a instituição possui um amplo acervo desses objetos. Desta forma, é nítida a intenção da instituição em promover o debate sobre o tema com o livro "Cultura Material e Patrimônio da Ciência e Tecnologia", idealizado pelo Grupo de Pesquisa Preservação de Acervos Culturais, grupo dedicado a diversas atividades relacionadas à problematização dos conceitos e da utilização de objetos da Ciência e Tecnologia como fontes documentais para a história da ciência.

O livro é uma coletânea de vinte e dois artigos, que abordam diversas realidades de instituições distintas sobre a temática da cultura material da Ciência e Tecnologia. Ele se divide em sete eixos temáticos: "Estudo de cultura material e as coleções museológicas", "Coleções de objetos de C\&T", "Coleções de objetos astronômicos", "Patrimônio Tecnológico Industrial”, "Coleções biológicas: papel estratégico e uso para pesquisa", "Coleções e Divulgação Científica" e "Patrimônio Intangível".

$O$ artigo que inaugura o livro, fora dos eixos temáticos, mas como texto introdutório, é de Pedro Paulo Funari e Aline Vieira de Carvalho, que buscam, a partir dos

O conceito de semióforo foi apresentado por Pomian (1984) para designar objetos que estão fora do circuito utilitário e são dotados de significado.

Classificação de P. McManus (apud Cazelli et al., 2003).

3 Essas exposições tinham o objetivo de apresentar o desenvolvimento das nações e, consequentemente, expunham invenções e máquinas.

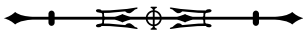


paradigmas sociais originados na década de 1960, entender os conceitos de cultura material e patrimônio na dimensão política da seleção do patrimônio da Ciência e Tecnologia.

$O$ primeiro tema possui três textos e inicia com o trabalho de Maria Cristina Oliveira Bruno, que, adentrando o universo das coleções museológicas, busca apresentar a importância dos estudos da cultura material para a organização das coleções. $\bigcirc$ artigo de Cecília Helena Salles de Oliveira enfatiza aspectos da representação e da construção da memória presente, principalmente, nos museus de história. $O$ último texto, da arqueóloga Maria Dulce Gaspar, faz uma analogia entre conceituações de sambaquis e de cachimbos para entender as diversas nuances da cultura material e suas interpretações feitas pela arqueologia.

Já o segundo eixo temático, composto por quatro artigos, inicia com o trabalho de Martha Lourenço, que faz um panorama dos acervos de Ciência e Tecnologia das universidades de Portugal, principalmente das ciências ditas exatas e das engenharias. Segue-se artigo de Pedro Ruiz-Castell, que demonstra como as políticas espanholas estão se aproximando da ideia da cultura científica como patrimônio. $\bigcirc$ trabalho de Marcus Granato consiste em um panorama sobre o potencial das pesquisas sobre os objetos de Ciência e Tecnologia no Brasil, sendo este trabalho um contextualizador das perspectivas de desenvolvimento desse tipo de análise, refletindo indiretamente a ideologia da concepção do livro. Encerrando o segundo eixo temático, Maria Celina Soares de Mello e Silva aborda a importância da Arquivologia para a organização de arquivos de laboratórios, para a compreensão do universo científico no qual os documentos são gerados e para a sua preservação.

O terceiro eixo temático abrange três artigos, sendo o primeiro de Sixto Ramón Giménez Benítez, que traça um panorama do patrimônio dos observatórios da Argentina. É seguido por trabalho de Janaína Lacerda Furtado, que faz um histórico do laboratório de química do Imperial Observatório do Rio de Janeiro. O eixo se encerra com o artigo de Maria Alice Ciocca de Oliveira e Marcus Granato, abordando os objetos de Ciência e Tecnologia existentes no Observatório do Valongo, vinculado à Universidade Federal do Rio de Janeiro.

No quarto eixo temático, com quatro artigos, Maria Letícia Mazzucchi Ferreira inicia a questão do patrimônio industrial e suas diversas concepções. No trabalho conseguinte, José Neves Bittencourt, a partir de dados históricos ligados ao Museu Histórico Abílio Barreto, de Belo Horizonte, propõe um olhar diferenciado dos cientistas para com os museus, usando a analogia como metodologia. José Sergio Lopes e Rosilene Alvim conjugam as questões da memória social operária com aspectos da patrimonialização industrial. O eixo temático se encerra com o trabalho de Felipe Koeller Rodrigues Vieira e Marcus Granato, que aborda o patrimônio aeronáutico em seus diversos aspectos.

O quinto tema possui três artigos e inicia com - trabalho de Marcio Rangel, que aborda a coleção entomológica de Costa Lima, do Instituto Oswaldo Cruz. Dando sequência, o artigo de Roberta Nobre da Câmara, Marcus Granato e Magali Romero Sá aborda as coleções microbiológicas da Fundação Oswaldo Cruz. O último trabalho, de Ariane Luna Peixoto, Maria Regina de Vasconcellos Barbosa, Dora Ann Lange Canhos e Leonor Costa Maia, trata da importância das coleções botânicas, principalmente no Brasil.

No sexto eixo são encontrados três artigos, sendo o trabalho de Guaracira Gouvêa um ensaio sobre cultura material e divulgação científica. Segue-se artigo de José Mauro Matheus Loureiro, sobre a socialização do patrimônio e museus de Ciência e Tecnologia, fazendo uma análise por meio do conceito de socialização da informação. Encerrando o eixo, Maria Lucia de Niemeyer Matheus Loureiro fala das contribuições das coleções museológicas para a divulgação da ciência.

O último eixo temático, com um único artigo, o de Luiz Carlos Borges, aborda o patrimônio intangível, considerando as tecnologias científicas e da informação no processo técnico-cultural.

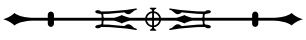


O panorama que os sete eixos temáticos constroem constitui uma estrutura baseada em aspectos transdisciplinares, em que diversos campos do conhecimento acabam por contribuir para novos olhares sobre a cultura material da Ciência e Tecnologia. O livro também demonstra a força que este tipo de pesquisa vem ganhando no cenário brasileiro e internacional, sendo esta publicação, com certeza, uma porta aberta para que trabalhos similares sejam produzidos.

\section{REFERÊNCIAS}

CAZELLI, Sibele; MARANDINO, Martha; STUDART, Denise Coelho. Educação e comunicação em museus de ciência: aspectos históricos, pesquisa e prática. In: GOUVÊA, Guaracira; MARANDINO, Martha; LEAL, Maria Cristina (Orgs.). Educação e Museus: a construção social do caráter educativo dos Museus de Ciência. Rio de Janeiro: Access, 2003. p. 83-106.

POMIAN, Krzysztof. Colecção. In: ROMANO, Ruggiero (Dir.). Enciclopédia Einaudi: Memória - História. Lisboa: Imprensa Nacional/Casa da Moeda, 1984. v. 1, p. 51-86. 